\title{
Perinatal and Socioeconomic Risk Factors for Variable and Persistent Cognitive Delay at 24 and 48 Months of Age in a National Sample
}

\author{
Marianne M. Hillemeier • Paul L. Morgan • \\ George Farkas $\cdot$ Steven A. Maczuga
}

Published online: 12 August 2010

(C) The Author(s) 2010. This article is published with open access at Springerlink.com

\begin{abstract}
The objective of this paper is to examine patterns of cognitive delay at 24 and 48 months and quantify the effects of perinatal and sociodemographic risk factors on persistent and variable cognitive delay. Using data from 7,200 children in the Early Childhood Longitudinal Study, Birth Cohort (ECLS-B), multiple logistic regression models identified significant predictors of low cognitive functioning at 24 and 48 months. Additional multiple logistic models predicting cognitive delay at 48 months were estimated separately for children with and without delay at 24 months. Of the nearly 1,000 children delayed at 24 months, $24.2 \%$ remained delayed by 48 months; $7.9 \%$ of the children not delayed at 24 months exhibited delay at 48 months. Low and very low birthweight increased cognitive delay risk at 24 , but not 48 months. Low maternal education had a strongly increasing effect $(\mathrm{OR}=2.3$ at
\end{abstract}

\footnotetext{
M. M. Hillemeier ( $₫)$

Department of Health Policy and Administration, Pennsylvania State University, 504S Ford Building, University Park, PA 16802, USA

e-mail: mmh18@psu.edu

\section{P. L. Morgan}

Department of Educational Psychology, School Psychology, and Special Education, Pennsylvania State University, 211 Cedar Building, University Park, PA 16802, USA

e-mail: paulmorgan@psu.edu

G. Farkas

Department of Education, 2070 Education, University of California, Irvine, Mailcode 5500, Irvine, CA 92697, USA

e-mail: gfarkas@uci.edu

\section{S. A. Maczuga}

Population Research Institute, Pennsylvania State University, 814 Oswald, University Park, PA 16802, USA

e-mail: sam21@pop.psu.edu
}

24 months, OR $=13.7$ at 48 months), as did low family income ( $\mathrm{OR}=1.4$ at 24 months, $\mathrm{OR}=7.0$ at 48 months). Among children delayed at 24 months, low maternal education predicted delay even more strongly at 48 months $(\mathrm{OR}=30.5)$. Low cognitive functioning is highly dynamic from 24 to 48 months. Although gestational factors including low birthweight increase children's risk of cognitive delay at 24 months, low maternal education and family income are more prevalent in the pediatric population and are much stronger predictors of both persistent and emerging delay between ages 24 and 48 months.

Keywords Cognitive development - Low birthweight . Socioeconomic factors - Developmental delay $\cdot$ Maternal education

The early childhood years are characterized by dramatic growth in children's cognitive functioning. For most children, such growth culminates in the acquisition of the knowledge and complex processing abilities required to succeed in structured school settings. However, a significant proportion of children fail to achieve this optimal developmental trajectory and instead experience delays that may or may not be recognized prior to their enrollment in kindergarten. The early onset of cognitive delay lowers children's school readiness, and can also have persistent and cascading effects that result in differentially poorer mental and physical health throughout childhood and beyond [1,2].

Pediatric health care providers are frequently the first health professionals in a position to observe early delays in children's cognitive development, and therefore to facilitate timely intervention. However, there is little populationbased evidence to guide practitioners in identifying 
subpopulations of children at risk, and to inform them about the relative importance of various risk factors for cognitive delay during the years prior to school entry. On one hand, numerous clinical follow-up studies of children born prematurely and at low birthweight show that these children are more likely to display low educational achievement in school [3-10] and into adulthood [11]. As a result, these children are relatively more likely to be referred for early intervention services [12]. However, many additional factors are also hypothesized to contribute to children's risk of cognitive delay, yet have not been systematically examined. Some of these factors, such as lower maternal education and family socioeconomic status [13-15], are more prevalent than preterm birth and low birthweight among the general population of children [16], and as such may be more likely to be risk factors for lower cognitive functioning in children seen in primary care practices [17].

Another important limitation of existing research is that there are very few studies of child development that analyze nationally-representative data over time. Of those studies that are longitudinal, most are constrained by relatively small sample sizes to aggregate data over large childhood age ranges rather than focusing on developmental assessment at specific ages [18-20]. Consequently, pediatric researchers and clinicians do not know the extent to which the onset of cognitive delay as early as age 2 increases the likelihood of lower school readiness during the children's preschool years.

Gaining a greater understanding of the influences on children's early cognitive development is particularly important in view of increasing evidence documenting long-term adverse health and social consequences of impaired development $[1,2,21]$, and the considerable benefits of early intervention [22-24]. The purpose of the present study is to quantify risk factors for cognitive delay in children between 24 and 48 months of age, and in particular risk factors associated with persistent and emerging cognitive delay. Identifying which groups of children are likely to experience delays in their cognitive growth will help pediatricians more effectively target their screening and intervention efforts. The study analyses are based on a new nationally representative, longitudinal dataset, the Early Childhood Longitudinal Study, Birth Cohort (ECLS-B) that includes multiple measures of gestational, birth, and socio-demographic characteristics as well as in-person child development assessments and extensive parental interviews. Analyses of this populationbased data provide the most rigorously derived estimates available to date of the dynamics and risk factors for cognitive delay during a time period when pediatricians' screening, monitoring, and intervention efforts are likely to have the greatest impact.

\section{Methods}

Data and Sample

The ECLS-B includes data from a cohort of $\sim 10,200$ children born in the US in 2001. Note that all sample sizes reported in this paper have been rounded to the nearest 50 , as specified by ECLS-B data confidentiality requirements (which are available at the ECLS-B website: http://nces. ed.gov/ecls/birthdatainformation.asp). The ECLS-B sample was selected from birth certificate records and includes oversamples of Asian and Pacific Islanders, Native Americans and Alaska Natives, low birthweight (1,500-2,500 g) and very low birthweight $(<1,500 \mathrm{~g})$ children, and multiple births. Sample weights are provided in the ECLS-B dataset to allow for calculation of nationally-representative estimates. The ECLS-B study protocol includes direct developmental assessments and interviews with family members when children are 9 months, 24 months, and 48 months of age. Data used in the present analyses were gathered at the 24 and 48 month assessments.

In this study, we restricted the analytic sample to the approximately 7,200 children having cognitive assessment data from the 24 and 48 month developmental assessments, as well as data for each of the other variables included in the multivariate models. Thus, the analytic sample excluded some children who participated in the ECLS-B study but had missing data on variables of interest. However, those children who were excluded were generally similar to those included in the analytic sample on most observed socioeconomic characteristics. Data for the 48 month developmental assessments were slightly more likely to be missing among males and among black children, resulting in analytic sample sizes for these groups that were smaller than their representation in the full sample by 1.2 percent and 3 percent, respectively.

\section{Measures}

\section{Low Cognitive Functioning}

The outcome of interest, delayed cognitive functioning, was quantified based on standardized cognitive assessments administered to children at the 24 and 48 month survey waves. At 24 months, the mental scale of the Bayley Short Form-Research Edition (BSF-R) was used. This is a modified version of the Bayley Scales of Infant Development, Second Edition (BSID-II), which is designed for use in children from birth to 36 months of age. In both the BSID-II and the BSF-R, the mental score is based on trained interviewer assessments of age-appropriate cognitive development as manifested in tasks demonstrating memory, habituation, preverbal communication, problem-solving, 
and concept attainment. The shortened BSF-R was extensively tested to ensure that the psychometric properties of the BSID-II were maintained and that it accurately measured children's performance over the entire ability distribution. The overall IRT reliability coefficient for the BSF-R mental scale was 0.98. A mental scale score is provided in the ECLS-B, along with the child's age at the time of administration. For children born preterm, age at administration was recorded as chronological age minus the number of weeks preterm. A dichotomous variable was created having a value of 1 for children scoring in the lowest $10 \%$ of the BSF-R scale distribution and 0 otherwise. This 10th percentile cut-point has been used to identify cognitive delay in previous research by our team [25] and by others [26-28]. We also tested alternative specifications using 5 and $15 \%$ as cut points. The patterns of results using these alternative cut points were consistent with the results we report using the $10 \%$ cut point.

Administration of the Bayley assessment was no longer age-appropriate by the 48 month time point. Instead, a standardized assessment battery measuring literacy, math concepts, color knowledge, and receptive vocabulary skills was administered. Thus, the 48 months battery consisted of items relating more directly to preschool-aged children's academic school readiness. The battery incorporated items from a number of standardized assessments developed for use in other large studies of child development such as the Head Start Impact Study [29], and included elements of the Peabody Picture Vocabulary Test [30], the Preschool Comprehensive Test of Phonological and Print Processing [31], the PreLAS 2000 [32], and the Test of Early Mathematics Ability-3 [33]. We converted children's scores on the measures of literacy, math concepts, color knowledge, and receptive vocabulary into $z$-scores and summed them to produce a summary cognitive score. Similar to the procedure used for the BSF-R scores, we created a dichotomous variable that was given a value of 1 for those scoring in the lowest $10 \%$ of the distribution, and 0 otherwise.

\section{Predictor Variables of Interest}

Socio-demographic data were collected in parent interviews and from birth certificates, and variables were included in the analyses capturing children's race/ethnic origin (nonHispanic white, non-Hispanic black, Hispanic, Asian, Native American, and other), maternal education (less than 9th grade, 9th-12th grade, high school graduate, some college or other training after high school, and 4-year college degree and above), family income (less than $\$ 10,000$, $\$ 10,001-20,000, \$ 20,001-\$ 40,000, \$ 40,001-\$ 75,000$, or over $\$ 75,000)$, maternal age, and marital status. Birth certificate records provided data on medical risk factors during pregnancy (quantified as a count of problems present including incompetent cervix, acute or chronic lung disease, chronic hypertension, pregnancy-induced hypertension, eclampsia, diabetes, hemoglobinopathy, cardiac disease, anemia, renal disease, genital herpes, oligohydramnios, uterine bleeding, $\mathrm{Rh}$ sensitization, previous birth weighing $4,000+\mathrm{g}$, or previous preterm birth), behavioral risk factors during pregnancy (alcohol and tobacco use during pregnancy, coded as 1 if present and summed to form a scale that ranged from 0 to 2 ), obstetrical procedures (measured as a count of procedures including induction of labor, stimulation of labor, tocolysis, amniocentesis, and cesarean section), labor complications (measured as a count of complications including abruption placenta, anesthetic complications, dysfunctional labor, breech/malpresentation, cephalopelvic disproportion, cord prolapsed, fetal distress, excessive bleeding, fever of $>100^{\circ} \mathrm{F}$, moderate/ heavy meconium, precipitous labor $(<3 \mathrm{~h})$, prolonged labor ( $>24 \mathrm{~h}$ ), placental previa, or seizures during labor), multiple birth, preterm delivery (represented by two dichotomous indicator variables: (1) very preterm ( $\leq 32$ weeks) and (2) moderately preterm (33-36 weeks)), low birthweight (represented by 2 dichotomous indicator variables: (1) very low birthweight $(\leq 1,500 \mathrm{~g})$ and (2) moderately low birthweight (1,501-2,500 g), and presence of any congenital anomaly. Child age was included to control for variations in actual age at administration of the 24 and 48 month assessments.

\section{Analyses}

Descriptive analyses were conducted for study variables, as well as cross-tabulation of cognitive delay at 48 months by delay status at 24 months to assess the relative stability of cognitive delay over the two time points. Two nested multiple logistic regression models were estimated for each of these study time points to examine associations between low cognitive functioning and socio-demographic characteristics and gestational and birth-related factors. To identify potential differences between children with persistent and emerging delay over the study period, additional sets of multiple logistic models predicting cognitive delay at 48 months were estimated separately for children with and without delay at 24 months. Analyses were weighted to appropriately account for the oversampling of some population groups and the stratified cluster design of the ECLS-B. All analyses were performed with SAS version 9.1 statistical software.

\section{Results}

Table 1 provides descriptive statistics for the study sample, including gestational and birth factors, demographic 
Table 1 Demographic characteristics, gestational and birth factors, and cognitive test scores, early childhood longitudinal study-birth cohort (ECLS-B) study sample $(N=7,200)$

\begin{tabular}{|c|c|c|}
\hline & $\begin{array}{l}\text { Mean or } \\
\text { percent }^{\text {a }}\end{array}$ & $\begin{array}{l}\text { Standard } \\
\text { deviation }\end{array}$ \\
\hline Male & $50 \%$ & \\
\hline Child age (months), ECLS-B wave 2 & 24.39 & 1.16 \\
\hline Child age (months), ECLS-B wave 3 & 52.54 & 4.10 \\
\hline \multicolumn{3}{|l|}{ Ethnic origin } \\
\hline White, non-hispanic & $57 \%$ & \\
\hline Black & $14 \%$ & \\
\hline Hispanic & $22 \%$ & \\
\hline Asian & $3 \%$ & \\
\hline Native American & $0.4 \%$ & \\
\hline Other & $4 \%$ & \\
\hline \multicolumn{3}{|l|}{ Mother's education, 24 month assessment } \\
\hline Less than 9th grade & $3 \%$ & \\
\hline From 9 th to 12 th grade & $12 \%$ & \\
\hline High school graduate & $31 \%$ & \\
\hline Some training/college after high school & $27 \%$ & \\
\hline Four year college degree and above & $26 \%$ & \\
\hline \multicolumn{3}{|l|}{ Family income, 24 month assessment } \\
\hline Less than $\$ 10,000$ & $9 \%$ & \\
\hline Between $\$ 10,001$ and $\$ 20,000$ & $14 \%$ & \\
\hline Between $\$ 20,001$ and $\$ 40,000$ & $27 \%$ & \\
\hline Between $\$ 40,001$ and $\$ 75,000$ & $26 \%$ & \\
\hline At or above $\$ 75,001$ & $24 \%$ & \\
\hline \multicolumn{3}{|l|}{ Mother's education, 48 month assessment } \\
\hline Less than 9th grade & $3 \%$ & \\
\hline From 9 th to 12 th grade & $10 \%$ & \\
\hline High school graduate & $30 \%$ & \\
\hline Some training/college after high school & $30 \%$ & \\
\hline Four year college degree and above & $27 \%$ & \\
\hline \multicolumn{3}{|l|}{ Family income, 48 month assessment } \\
\hline Less than $\$ 10,000$ & $8 \%$ & \\
\hline Between $\$ 10,001$ and $\$ 20,000$ & $12 \%$ & \\
\hline Between $\$ 20,001$ and $\$ 40,000$ & $26 \%$ & \\
\hline Between $\$ 40,001$ and $\$ 75,000$ & $25 \%$ & \\
\hline At or above $\$ 75,001$ & $28 \%$ & \\
\hline Maternal age $=35$ or older & $14 \%$ & \\
\hline $\begin{array}{l}\text { Marital status }=\text { unmarried, } 48 \text { month } \\
\text { assessment }\end{array}$ & $32 \%$ & \\
\hline Medical risk factor(s) & 0.18 & 0.52 \\
\hline Behavioral risk factor(s) & 0.12 & 0.33 \\
\hline Obstetric procedure(s) & 0.59 & 0.68 \\
\hline Labor complication(s) & 0.36 & 0.67 \\
\hline Multiple birth & $3 \%$ & \\
\hline \multicolumn{3}{|l|}{ Gestation } \\
\hline Very preterm $\leq 32$ weeks & $2 \%$ & \\
\hline Moderately preterm 33-36 weeks & $9 \%$ & \\
\hline
\end{tabular}

Table 1 continued

\begin{tabular}{llc}
\hline & $\begin{array}{l}\text { Mean or } \\
\text { percent }^{\mathrm{a}}\end{array}$ & $\begin{array}{l}\text { Standard } \\
\text { deviation }^{-}\end{array}$ \\
\hline Birthweight & & \\
$\quad$ Very low birthweight $\leq 1,500 \mathrm{~g}$ & $1 \%$ & \\
$\quad \begin{array}{l}\text { Moderately low birthweight } \\
\quad \text { 1,501-2,500 grams }\end{array}$ & $6 \%$ & \\
Congenital anomaly & $5 \%$ & \\
Bayley mental score, 24 month assessment & 127.75 & 10.66 \\
Literacy score, 48 month assessment & 13.11 & 7.14 \\
Math score, 48 month assessment & 22.64 & 7.42 \\
Color knowledge score, 48 month assessment & 8.77 & 2.28 \\
Receptive vocabulary score, 48 month & 8.60 & 1.92 \\
$\quad$ assessment & & \\
48 Month assessment score & 53.12 & 16.00 \\
\hline
\end{tabular}

The Bayley mental score was used as the cognitive score at 24 months; at 48 months, literacy, math, color knowledge, and receptive vocabulary scores were converted into $z$-scores and summed

Sample size rounded to nearest 50 in accordance with ECLS-B data confidentiality requirements (available at http://nces.ed.gov/ecls/ birthdatainformation.asp)

a Estimates are weighted to take the complex sampling design into account

b Any congenital abnormality identified on the birth certificate

characteristics, and mean cognitive scores at the 24 and 48 month assessments. Of the $11 \%$ of children born preterm, 9 percentage points were due to those born between 33 and 36 weeks, and 2 percentage points were due to those born very preterm at 32 weeks gestation or fewer. Similarly, a small percentage $(1 \%)$ of the sample were born at very low birthweight $(\leq 1,500 \mathrm{~g})$, while $6 \%$ had moderately low birthweight (1,501-2,500 g). Male and female children were equally represented in the sample. White, non-Hispanic children comprised $57 \%$ of the total. The next largest ethnic groups, Hispanic and Black children, made up 22 and $14 \%$ of the sample, respectively.

Table 2 displays information for two groups of children. Data for the nearly 1,000 children who scored in the lowest $10 \%$ of the weighted cognitive score distribution at 24 months are shown in the top panel. The bottom panel contains data for children not in the low range at 24 months. Of the children classified as cognitively delayed at the 24 month assessment, only $24.2 \%$ remained delayed by 48 months. This indicates a high likelihood of improvement over time. Conversely, $7.9 \%$ of children who were not delayed at 24 months fell into the low range by 48 months. This indicates that the majority of children displaying cognitive delay at 24 months of age do not display atypically low levels of school readiness at 48 months of age. 
Table 2 Patterning of cognitive scores over time in early childhood, ECLS-B unweighted study sample $(N=7,200)$

\begin{tabular}{lccc}
\hline & $\begin{array}{l}\text { Number Not } \\
\text { Delayed at 48 Mo }\end{array}$ & $\begin{array}{l}\text { Number } \\
\text { Delayed at 48 Mo }\end{array}$ & $\begin{array}{c}\text { Percent (95\% CI) } \\
\text { Delayed at 48 Mo }\end{array}$ \\
\hline I. All children cognitively delayed at 24 Mo $(n=1,000)$ & 750 & 250 & $24.2^{\mathrm{a}}(21.6,27.0)$ \\
II. All children not cognitively delayed at 24 Mo $(n=6,250)$ & 5,750 & 500 & $7.9(7.2,8.6)$ \\
\hline
\end{tabular}

The Bayley mental score was used as the cognitive score at 24 months; at 48 months, literacy, math, color knowledge, and receptive vocabulary scores were converted into $z$-scores and summed. At both 24 and 48 months, cognitive delay was defined as falling in the lowest $10 \%$ of scores Cutoffs for the bottom $10 \%$ of scores at 24 and 48 months were determined from the weighted, full available sample of cases at each time point. (This, plus oversampling of low birth weight and multiple birth children accounts for the fact that the analysis sample contains more than 10\% delayed children at 24 months.)

All sample sizes in this table are rounded to the nearest 50 in accordance with ECLS-B data confidentiality requirements (available at http://nces.ed.gov/ecls/birthdatainformation.asp)

${ }^{a}$ Percentages and confidence intervals are calculated from actual sample sizes and have not been rounded

Table 3 shows logistic regression models predicting the child's cognitive delay status separately at 24 and 48 months. Two models are shown for each time point. The first model includes demographic information including sex, age, and race/ethnic origin. The second model also adds socioeconomic variables and characteristics of gestation and infant status at birth. The numbers shown are the effects of each predictor on the odds of a child displaying a low cognitive score, after statistically controlling for all of the other variables in the model.

Model 1, displaying findings from the 24 month assessment, indicates that male children were approximately twice as likely as female children to exhibit low cognitive functioning. Those children who were comparatively older at the time of the assessment were less likely to have lower scores. Compared to non-Hispanic white children, black, Hispanic, and Asian children, as well as those of other race/ethnic origins (with the exception of Native Americans) had significantly elevated odds of displaying cognitive delay.

Model 2 adds gestational and birth characteristics, as well as additional sociodemographic characteristics. Maternal education is a strong predictor of cognitive delay. Children of mothers in the lowest education category experiencing over twice the risk of low cognitive scores compared to children of highly educated mothers. Other significant predictors of cognitive delay at 24 months include multiple birth $(\mathrm{OR}=1.52)$ and being born at very low or moderately low birthweight $(\mathrm{OR}=4.38$ and $\mathrm{OR}=1.70$, respectively). The addition of socioeconomic and birth-related variables in Model 2 reduces the effects associated with black and Hispanic race/ethnicity, but does not completely account for those effects as race/ethnicity remains a statistically significant risk factor.

The effects of low maternal education become even stronger at 48 months. At this time point, and controlling for many other variables, children of mothers with the lowest educational attainment are more than 13 times more likely to be cognitively delayed than children of the most highly educated mothers. The odds ratios for the lower income categories are also significantly elevated. This indicates that income and education each exert independent effects on children's risk of displaying delayed cognitive functioning at 48 months. By 48 months, birthweight is no longer predictive of cognitive delay. However, gender and multiple birth remain significant, and having had obstetrical procedures at birth is associated with lower risk. Similar to the findings at 24 months, the estimated effects of race/ethnicity are generally reduced in magnitude but not eliminated after accounting for additional social and birth-related factors.

Table 4 shows estimated effects of risk factors for cognitive delay at 48 months, separately for children who were, and who were not cognitively delayed at 24 months. Looking first at those who were delayed at 24 months, the full model (Model 2) indicates that maternal education is an extremely strong risk factor for continued delay at 48 months $(\mathrm{OR}=30.49$ for lowest maternal education category, and 10.66 for the second-lowest category), with family income also shown to be important (OR $=7.58$ for the lowest income category and 4.17 for the second-lowest category). Very low birthweight is significant in Model 2, however race/ethnicity is not.

Among children who were not delayed at 24 months, the results of Model 2 show both similarities and differences with those who were delayed. One difference is that for those not delayed at 24 months, race/ethnic origin effects are larger and more likely to be statistically significant than for those who were delayed. These occur for blacks $(\mathrm{OR}=1.89)$, Hispanics $(\mathrm{OR}=2.87)$, and Native Americans $(\mathrm{OR}=3.31)$. Mother's education and family income effects are now smaller in magnitude than for the previously delayed, but still strikingly large overall. The effect for the lowest category of mother's education has an $\mathrm{OR}=11.46$, while the lowest category of family income 
Table 3 Logistic regression estimates (odds ratios) of displaying low cognitive scores at the 24 and 48 month assessments $(N=7,200)$
$* P \leq 0.05, * * P \leq 0.01$,

*** $P \leq 0.001$

Literacy, math, color knowledge, and receptive vocabulary scores were converted into $z$-scores and summed to produce cognitive score at 48 months; lowest $10 \%$ were defined as low

Bayley mental score was used as cognitive score at 24 months; lowest $10 \%$ were defined as low

Sample size rounded to the nearest 50 in accordance with ECLS-B data confidentiality requirements (available at http://nces.ed.gov/ecls/ birthdatainformation.asp)

\begin{tabular}{|c|c|c|c|c|}
\hline & \multicolumn{2}{|c|}{24 Mo assessment } & \multicolumn{2}{|c|}{48 Mo assessment } \\
\hline & Model 1 & Model 2 & Model 1 & Model 2 \\
\hline Male & $1.93 * * *$ & $2.00 * * *$ & $1.55^{* * *}$ & $1.66^{* * * *}$ \\
\hline Child age (months) & $0.66 * * *$ & $0.64 * * *$ & $0.86 * * *$ & $0.83 * * *$ \\
\hline \multicolumn{5}{|l|}{ Ethnic origin } \\
\hline Black & $3.00 * * *$ & $1.92 * * *$ & $4.47 * * *$ & $1.97 * * *$ \\
\hline Hispanic & $2.89 * * *$ & $2.04 * * *$ & $5.69 * * *$ & $2.61 * * *$ \\
\hline Asian & $2.45 * * *$ & $2.74 * * *$ & $1.68 *$ & 1.61 \\
\hline Native American & 1.96 & 1.46 & $4.45^{* * *}$ & $2.37 * * *$ \\
\hline Other & $1.85^{*}$ & 1.49 & $2.40 * * *$ & $1.70 *$ \\
\hline White, non-hispanic & 1.00 (ref) & 1.00 (ref) & 1.00 (ref) & 1.00 (ref) \\
\hline \multicolumn{5}{|l|}{ Mother's education at corresponding assessment } \\
\hline Less than 9th grade & & $2.33 * *$ & & $13.65 * * *$ \\
\hline From 9 th to 12 th grade & & $2.45 * * *$ & & $6.88 * * *$ \\
\hline High school graduate & & $1.97 * * *$ & & $3.13 * * *$ \\
\hline Some training/college after high school & & $1.81 * *$ & & $1.83 *$ \\
\hline Four year college degree and above & & 1.00 (ref) & & 1.00 (ref) \\
\hline \multicolumn{5}{|l|}{ Family income at corresponding assessment } \\
\hline Less than $\$ 10,000$ & & 1.43 & & $7.01 * * *$ \\
\hline Between $\$ 10,001$ and $\$ 20,000$ & & 1.56 & & $5.13 * * *$ \\
\hline Between $\$ 20,001$ and $\$ 40,000$ & & 1.31 & & $3.92 * * *$ \\
\hline Between $\$ 40,001$ and $\$ 75,000$ & & 1.10 & & $2.52 * *$ \\
\hline At or above $\$ 75,001$ & & 1.00 (ref) & & 1.00 (ref) \\
\hline Maternal age $=35$ or older & & 0.90 & & 0.96 \\
\hline Marital status $=$ unmarried, 48 month assessment & & 1.10 & & 0.99 \\
\hline Medical risk factor(s) & & 0.98 & & 0.89 \\
\hline Behavioral risk factor(s) & & 0.79 & & 0.87 \\
\hline Obstetric procedure(s) & & 0.85 & & $0.83^{*}$ \\
\hline Labor complication(s) & & 1.04 & & 1.03 \\
\hline Multiple birth & & $1.52 * *$ & & $1.52 *$ \\
\hline \multicolumn{5}{|l|}{ Gestation } \\
\hline Very preterm $\leq 32$ weeks & & 1.52 & & 1.86 \\
\hline Moderately preterm 33-36 weeks & & 1.07 & & 1.10 \\
\hline \multicolumn{5}{|l|}{ Birthweight } \\
\hline Very low birthweight & & $4.38 * * *$ & & 1.10 \\
\hline Moderately low birthweight & & $1.70 * * *$ & & 1.17 \\
\hline Congenital anomaly & & 1.19 & & 1.27 \\
\hline
\end{tabular}

has an $\mathrm{OR}=6.20$. Very preterm birth $(\mathrm{OR}=3.07)$ and multiple birth $(\mathrm{OR}=1.48)$ are also associated with elevated risk for low cognitive scores at 48 months in this group of children, and a history of obstetric procedures is associated with lower risk $(\mathrm{OR}=0.81)$.

Collectively, these analyses indicate that particular socioeconomic factors (i.e., low maternal education, low family income) strongly elevate a child's risk for cognitive delay. This is the case for each time period separately, and, when separate analyses are run according to cognitive delay status at 24 months, for both persistent and emerging delay. Such is not the case for the gestational and birth characteristics, where effects become much weaker when predicting cognitive delay at 48 months. The importance and regularity of the effects of the socio-economic factors are also underscored by the fact that they display a monotonic increasing pattern, in that each increase in either the mother's education level or the family's income corresponds to a decrease in a child's risk of persistent or variable cognitive delay. The largest of these effects occurs at the very lowest level of mother's education, when predicting child outcomes at 48 months. 
Table 4 Logistic regression estimates (odds ratios) of displaying low cognitive scores at 48 months, shown separately for children with and without cognitive delay at 24 months
$* P \leq 0.05, * * P \leq 0.01$,

*** $P \leq 0.001$

Literacy, math, color knowledge, and receptive vocabulary scores were converted into $z$-scores and summed to produce cognitive score at 48 months; lowest $10 \%$ were defined as low

Bayley mental Score was used as cognitive score at 24 months; lowest $10 \%$ were defined as low

a All sample sizes in this table are rounded to the nearest 50 in accordance with ECLS-B data confidentiality requirements (available at http://nces.ed.gov/ecls/ birthdatainformation.asp)

\begin{tabular}{|c|c|c|c|c|}
\hline & \multicolumn{2}{|c|}{$\begin{array}{l}\text { Children with low } \\
\text { cognitive score at the } \\
24 \text { month assessment } \\
\left(n=1,000^{\mathrm{a}}\right)\end{array}$} & \multicolumn{2}{|c|}{$\begin{array}{l}\text { Children with non-low } \\
\text { cognitive score at the } \\
24 \text { month assessment } \\
(n=6,250)\end{array}$} \\
\hline & Model 1 & Model 2 & Model 1 & Model 2 \\
\hline Male & 0.88 & 1.06 & $1.57 * * *$ & $1.68 * * *$ \\
\hline Child age (months) & $0.85 * * *$ & $0.82 * * *$ & $0.85^{* * *}$ & $0.83 * * *$ \\
\hline \multicolumn{5}{|l|}{ Ethnic origin } \\
\hline Black & $2.30 * *$ & 1.60 & $4.39 * * *$ & $1.89 * * *$ \\
\hline Hispanic & $2.32 * *$ & 1.36 & $6.18 * * *$ & $2.87 * * *$ \\
\hline Asian & 0.88 & 1.10 & 1.73 & 1.54 \\
\hline Native American & 0.86 & 0.38 & $5.66 * * *$ & $3.31 * * *$ \\
\hline Other & $3.36^{*}$ & 2.16 & $2.00 *$ & 1.40 \\
\hline White, non-hispanic & $1.00(\mathrm{ref})$ & 1.00 (ref) & 1.00 (ref) & 1.00 (ref) \\
\hline \multicolumn{5}{|l|}{ Mother's education at corresponding assessment } \\
\hline Less than 9th grade & & $30.49 * * *$ & & $11.46^{* * *}$ \\
\hline From 9 th to 12 th grade & & $10.66 * * *$ & & $5.93 * * *$ \\
\hline High school graduate & & $5.61 * *$ & & $2.62 * *$ \\
\hline Some training/college after high school & & 3.03 & & 1.56 \\
\hline Four year college degree and above & & 1.00 (ref) & & 1.00 (ref) \\
\hline \multicolumn{5}{|l|}{ Family income at corresponding assessment } \\
\hline Less than $\$ 10,000$ & & $7.58 * * *$ & & $6.20 * * *$ \\
\hline Between $\$ 10,001$ and $\$ 20,000$ & & $4.17 * *$ & & $4.85 * * *$ \\
\hline Between $\$ 20,001$ and $\$ 40,000$ & & $3.19 *$ & & $3.86 * * *$ \\
\hline Between $\$ 40,001$ and $\$ 75,000$ & & $3.17 * *$ & & $2.31 *$ \\
\hline At or above $\$ 75,001$ & & $1.00(\mathrm{ref})$ & & 1.00 (ref) \\
\hline Maternal age $=35$ or older & & 1.22 & & 0.89 \\
\hline Marital status $=$ unmarried, 48 month assessment & & 0.78 & & 1.02 \\
\hline Medical risk factor(s) & & 1.36 & & 0.77 \\
\hline Behavioral risk factor(s) & & 1.17 & & 0.83 \\
\hline Obstetric procedure(s) & & 0.91 & & $0.81 *$ \\
\hline Labor complication(s) & & 0.98 & & 1.04 \\
\hline Multiple birth & & 1.25 & & $1.48^{*}$ \\
\hline \multicolumn{5}{|l|}{ Gestation } \\
\hline Very preterm $\leq 32$ weeks & & 0.33 & & $3.07 * *$ \\
\hline Moderately preterm 33-36 weeks & & 0.82 & & 1.17 \\
\hline \multicolumn{5}{|l|}{ Birthweight } \\
\hline Very low birthweight & & $3.42 *$ & & 0.56 \\
\hline Moderately low birthweight & & 1.26 & & 1.13 \\
\hline Congenital anomaly & & 1.07 & & 1.26 \\
\hline
\end{tabular}

\section{Discussion}

The goal of this study was to identify patterns of cognitive delay in the US child population between 24 and 48 months of age, and quantify the factors associated with increased risk of experiencing such delay. The analyses indicate that patterns of development in early childhood are highly dynamic. The findings provide evidence for a high likelihood of "recovery" among children who exhibit cognitive delay at 24 months, with $76 \%$ testing in the non-delayed range by 48 months. The analyses also identified a group of children who repeatedly display cognitive delay during the toddler to preschool period. The estimates indicate that about one-quarter of those delayed at 24 months will also experience delay at 48 months (i.e., persistently delayed children). These children will likely require early intervention services if they are to successfully meet the increasing demands of primary school classrooms.

Multivariate analyses involving children delayed at 24 months indicate that low levels of maternal education 
and family income are by far the most salient risk factors for continued delay at 48 months. These factors are associated with dramatic increases in risk of 30-fold (mother's education) and sevenfold (family income), respectively. In contrast, very low birthweight status is associated with a more modest but still significant threefold increase in risk. Among children without delay at 24 months, socio-demographic factors including low maternal education and low family income also had the strongest effects on the risk of delay at 48 months, while perinatal characteristics including prematurity and multiple gestation were associated with lesser but still significantly elevated odds of delay.

The analyses presented here provide important new evidence about the patterning and relative importance of socio-demographic and perinatal factors in determining the risk of cognitive delay over time within the general population of young children. Much previous research about the adverse effects of perinatal factors on subsequent child development has been based on follow-up of clinical samples of low and very low birthweight children [5, 9, 34-37], who are often compared with similar numbers of normal birthweight children matched on demographic characteristics [9] or selected from regional samples [5]. Consistent with the present analyses, those prior studies identify persistent negative effects of low birthweight and prematurity on cognitive development [3,6]. Although these studies provide valuable information, they do not directly contrast the relative magnitude of these gestational and birth factors with the risks of cognitive delay associated with socioeconomic disadvantage among young children who are seen in general pediatric practice. Population-level research on developmental outcomes has generally been limited to secondary analysis of datasets such as the National Health and Nutrition Examination Survey [18], the National Health Interview Survey [19], and the Panel Study of Income Dynamics [20], in which small sample sizes necessitate pooling data from children of widely varying ages, often over both child and adolescent age ranges.

The present analyses underscore the strong effects of lower socioeconomic status, including lower maternal education and family income, on children's developmental risk. In particular, children with cognitive delay at 24 months who have less educated mothers are at markedly elevated risk of persistent delay through 48 months. Lower socioeconomic status is known to be associated with a range of exposures that can adversely influence cognitive development. These exposures include suboptimal nutritional status, both in overall caloric intake and with regard to specific nutrients needed for central nervous system functioning including iron, iodine and essential fatty acids [38-41], as well as increased incidence of chronic health conditions such as asthma [42]. Economically disadvantaged families are also more likely to live in neighborhoods that contain sources of lead [43], PCBs [44], and other toxins that can impair cognitive functioning. Lower socioeconomic status is also associated with less optimal home [13] and childcare [45] environments that tend to provide less cognitive stimulation [46]. For example, mothers with lower education levels typically use both lower quantity and quality vocabularies when interacting with their children [47]. Children in low-income families tend to watch TV more frequently [48], and often lack access to storybooks and other types of print material $[49,50]$.

The finding in this study that black, Hispanic, and Native American children are at increased risk of emerging delay after taking family income and education into account is consistent with findings that minority families are differentially more likely to experience adverse healthrelated and environmental exposures than white families of similar socioeconomic status [51,52]. Culturally diverse and non-English-speaking families also tend to have reduced access to and utilization of high quality pediatric health care that could counteract or buffer at least some of the effects of adverse physical and environmental exposures $[53,54]$.

The study findings have a number of practical implications for providers of pediatric health care. First, universal and comprehensive developmental screening in pediatric practice is critical for detecting early developmental delays [55]. A recent survey of pediatricians, however, indicates that only about a quarter adhere to current screening guidelines [56], which call for standardized developmental screening tests at 9,18 , and 24 or 30 months of age, and screening for school readiness at age 4 [55]. Moreover, findings of the present study suggest that this recommended timetable may be insufficient for timely identification of cognitive delay in socioeconomically disadvantaged populations. In addition to standardized testing, evidence suggests that systematically eliciting and evaluating parental concerns about their children's developmental progress at each well-child care visit is a highly beneficial component of surveillance [57].

Results of the present study also underscore the importance of strategies to facilitate cognitive development. In reviewing the evidence base for primary health care services to promote early child development, Regalado and Halfon [57] found support for the efficacy of anticipatory guidance encouraging positive parent-child contact through education about children's normal social development and emphasizing the importance of responsive reciprocal interactions. The incorporation in pediatric practices of structured programs such as Reach Out and Read that facilitate interactive reading among parents and children have also been found to increase children's cognitive and language test scores [58, 59]. Pediatric 
practitioners can also stress the importance of high quality child care in promoting child development, and provide information to parents about the components of quality programs [60].

The present study has several limitations. Gestational and birth information comes from birth certificates, which although widely used may contain erroneous information, especially concerning complications of pregnancy and delivery, prenatal substance use, and congenital abnormalities (some of which may not be recognized until after the newborn period) [61]. Delayed cognitive functioning was measured with different instruments at the two study time points. This was because the standardized cognitive assessment included in the ECLS-B at 24 months, the short form research version of the Bayley assessment, was not age-appropriate for administration to 48 month olds. In its place, the designers of the ECLS-B administered ageappropriate tests of early literacy, mathematics, color knowledge, and receptive vocabulary at 48 months. Although we cannot directly assess how use of different assessments at the two time points may have influenced the results, our strategy of specifying a cutoff of the 10th percentile of standardized score to identify delay has been used in other research [26], and it is reassuring that tests of alternative 5 and 15 percentile cutoff values yielded similar patterns of results.

In conclusion, this study underscores the dynamic nature of cognitive developmental progress from 24 to 48 months of age. Although low birthweight increases the risk of cognitive delay, especially at 24 months, socioeconomic disadvantage is more common in the pediatric population and is by far a much stronger predictor of persistent as well as emerging delay. Comprehensive developmental screening in pediatric practice is needed, especially in low-income subpopulations, to identify children who are experiencing delays and initiate ameliorative action.

Open Access This article is distributed under the terms of the Creative Commons Attribution Noncommercial License which permits any noncommercial use, distribution, and reproduction in any medium, provided the original author(s) and source are credited.

\section{References}

1. Martin, L. T., Fitzmaurice, G. M., Kindlon, D. J., \& Buka, S. L. (2004). Cognitive performance in childhood and early adult illness: A prospective cohort study. Journal of Epidemiology and Community Health, 58(8), 674-679.

2. Clark, D. O., Stump, T. E., Miller, D. K., \& Long, J. S. (2007). Educational disparities in the prevalence and consequence of physical vulnerability. Journals of Gerontology, Series B, Psychological Science and Social Science, 62(3), S193-S197.

3. Hack, M., Klein, N. K., \& Taylor, H. G. (1995). Long-term developmental outcomes of low birth weight infants. The Future of Children, 5(1), 176-196.
4. Bhutta, A. T., Cleves, M. A., Casey, P. H., Cradock, M. M., \& Anand, K. J. (2002). Cognitive and behavioral outcomes of school-aged children who were born preterm: A meta-analysis. Journal of the American Medical Association, 288(6), 728-737.

5. McCormick, M. C., Brooks-Gunn, J., Workman-Daniels, K., Turner, J., \& Peckham, G. J. (1992). The health and developmental status of very low-birth-weight children at school age. Journal of the American Medical Association, 267(16), 2204-2208.

6. Reichman, N. E. (2005). Low birth weight and school readiness. The Future of Children, 15(1), 91-116.

7. Breslau, N., Chilcoat, H., DelDotto, J., Andreski, P., \& Brown, G. (1996). Low birth weight and neurocognitive status at six years of age. Biological Psychiatry, 40(5), 389-397.

8. Breslau, N., Paneth, N. S., \& Lucia, V. C. (2004). The lingering academic deficits of low birth weight children. Pediatrics, 114(4), $1035-1040$

9. Saigal, S., Szatmari, P., Rosenbaum, P., Campbell, D., \& King, S. (1991). Cognitive abilities and school performance of extremely low birth weight children and matched term control children at age 8 years: A regional study. Journal of Pediatrics, 118(5), 751-760.

10. Teplin, S. W., Burchinal, M., Johnson-Martin, N., Humphry, R. A., \& Kraybill, E. N. (1991). Neurodevelopmental, health, and growth status at age 6 years of children with birth weights less than 1001 grams. Journal of Pediatrics, 118(5), 768-777.

11. Hack, M. (2006). Young adult outcomes of very-low-birth-weight children. Seminars in Fetal and Neonatal Medicine, 11(2), 127-137.

12. Silverstein, M., Sand, N., Glascoe, F. P., Gupta, V. B., Tonniges, T. P., \& O’Connor, K. G. (2006). Pediatrician practices regarding referral to early intervention services: Is an established diagnosis important? Ambulatory Pediatrics, 6(2), 105-109.

13. Brooks-Gunn, J., \& Duncan, G. J. (1997). The effects of poverty on children. The Future of Children, 7(2), 55-71.

14. Hackman, D. A., \& Farah, M. J. (2009). Socioeconomic status and the developing brain. Trends in Cognitive Sciences, 13(2), $65-73$.

15. Kiernan, K. E., \& Huerta, M. C. (2008). Economic deprivation, maternal depression, parenting and children's cognitive and emotional development in early childhood. British Journal of Sociology, 59(4), 783-806.

16. Federal Interagency Forum on Child and Family Statistics. (2008). America's children in brief: Key national indicators of well-being. Washington, DC: US Government Printing Office.

17. Delgado, C. E. F., \& Scott, K. G. (2006). Comparison of referral rates for preschool children at risk for disabilities using information obtained from birth certificate records. Journal of Special Education, 40(1), 28-35.

18. Hediger, M. L., Overpeck, M. D., Ruan, W. J., \& Troendle, J. F. (2002). Birthweight and gestational age effects on motor and social development. Paediatric and Perinatal Epidemiology, 16(1), 33-46.

19. McCormick, M. C., Gortmaker, S. L., \& Sobol, A. M. (1990). Very low birth weight children: Behavior problems and school difficulty in a national sample. Journal of Pediatrics, 117(5), 687-693.

20. Boardman, J. D., Powers, D. A., Padilla, Y. C., \& Hummer, R. A. (2002). Low birth weight, social factors, and developmental outcomes among children in the United States. Demography, 39(2), 353-368.

21. Blackorby, J., \& Wagner, M. (1996). Longitudinal postschool outcomes of youth with disabilities. Findings from the National Longitudinal Transition Study. Exceptional Children, 62, $399-414$

22. Guralnick, M. J. (1996). The effectiveness of early intervention. Baltimore MD: PF Brooks Publishing. 
23. McCarton, C. M., Brooks-Gunn, J., Wallace, I. F., Bauer, C. R., Bennett, F. C., Bernbaum, J. C., et al. (1997). Results at age 8 years of early intervention for low-birth-weight premature infants. The Infant Health and Development Program. Journal of the American Medical Association, 277(2), 126-132.

24. Feldman, M. A. (2004). Early intervention: The essential readings. Malden MA: Blackwell.

25. Hillemeier, M. M., Farkas, G., Morgan, P. L., Martin, M. A., \& Maczuga, S. A. (2009). Disparities in the prevalence of cognitive delay: How early do they appear? Paediatric and Perinatal Epidemiology, 23(3), 186-198.

26. Dale, P. S., Price, T. S., Bishop, D. V., \& Plomin, R. (2003). Outcomes of early language delay: I. Predicting persistent and transient language difficulties at 3 and 4 years. Journal of Speech, Language, and Hearing Research, 46(3), 544-560.

27. Webster, R. I., Majnemer, A., Platt, R. W., \& Shevell, M. I. (2004). The predictive value of a preschool diagnosis of developmental language impairment. Neurology, 63, 2327-2331.

28. Jacobson, J. L., Jacobson, S. W., Sokol, R. J., \& Ager, J. W., Jr. (1998). Relation of maternal age and pattern of pregnancy drinking to functionally significant cognitive deficit in infancy. Alcohol Clinical and Experimental Research, 22(2), 345-351.

29. Puma, M., Bell, S., Shapiro, G., Broene, P., Cook, R., Friedman, J., et al. (2001). Building futures: The head start impact study, research design plan. Available at: http://www.acf.hhs.gov/ programs/opre/hs/impact_study/reports/impact_study/impactstdy_ resrch_plan.pdf.

30. Dunn, L. M., \& Dunn, L. M. (1997). Examiner's manual for the Peabody Picture Vocabulary Test-Third Edition. Circle Pines, MN: American Guidance Service.

31. Lonigan, C. J., Wagner, R. K., Torgesen, J. K., \& Rashotte, C. A. (2003). Preschool Comprehensive Test of Phonological and Print Processing. Austin, TX: PRO-ED.

32. Duncan, S. E., \& Avila, E. A. D. (1998). PreLAS. Monterey, CA: CTB/McGraw-Hill.

33. Ginsburg, H. P., \& Baroody, A. J. (2003). Test of Early Mathematics Ability-Third Edition. TX: PRO-ED.

34. Ment, L. R., Vohr, B., Allan, W., Katz, K. H., Schneider, K. C., Westerveld, M., et al. (2003). Change in cognitive function over time in very low-birth-weight infants. Journal of the American Medical Association, 289(6), 705-711.

35. Vohr, B. R., Wright, L. L., Dusick, A. M., Mele, L., Verter, J., Steichen, J. J., et al. (2000). Neurodevelopmental and functional outcomes of extremely low birth weight infants in the National Institute of Child Health and Human Development Neonatal Research Network, 1993-1994. Pediatrics, 105(6), $1216-1226$.

36. Hack, M., Weissman, B., Breslau, N., Klein, N., Borawski-Clark, E., \& Fanaroff, A. A. (1993). Health of very low birth weight children during their first eight years. Journal of Pediatrics, 122(6), 887-892.

37. Breslau, N., Chilcoat, H. D., Susser, E. S., Matte, T., Liang, K. Y., \& Peterson, E. L. (2001). Stability and change in children's intelligence quotient scores: A comparison of two socioeconomically disparate communities. American Journal of Epidemiology, 154(8), 711-717.

38. Krassner, M. B. (1986). Diet and brain function. Nutrition Review, 44(Suppl), 12-15.

39. Lozoff, B. (2007). Iron deficiency and child development. Food and Nutrition Bulletin, 28(4 Suppl), S560-S571.

40. Schurch, B. (1995). Malnutrition and behavioral development: The nutrition variable. Journal of Nutrition, $125(8$ Suppl), 2255S-2262S.

41. Uauy, R., Peirano, P., Hoffman, D., Mena, P., Birch, D., \& Birch, E. (1996). Role of essential fatty acids in the function of the developing nervous system. Lipids, 31(Suppl), S167-S176.
42. Bloom, B., Cohen, R. A., \& Freeman, G. (2009). Summary health statistics for US children: National Health Interview Survey. Vital and Health Statistics, 10(239), 1-80.

43. Bellinger, D. C. (2008). Very low lead exposures and children's neurodevelopment. Current Opinion in Pediatrics, 20(2), 172-177.

44. Stewart, P. W., Reihman, J., Lonky, E. I., Darvill, T. J., \& Pagano, J. (2003). Cognitive development in preschool children prenatally exposed to $\mathrm{PCBs}$ and $\mathrm{MeHg}$. Neurotoxicology and Teratology, 25(1), 11-22.

45. Magnuson, K. A., \& Waldfogel, J. (2005). Early childhood care and education: Effects on ethnic and racial gaps in school readiness. The Future of Children, 15(1), 169-196.

46. Eamon, M. K. (2002). Effects of poverty on mathematics and reading achievement of young adolescents. The Journal of Early Adolescence, 22(1), 49-74.

47. Hart, B., \& Risley, T. R. (1995). Meaningful differences in the everyday experience of young American children. Baltimore MD: Paul H. Brooks.

48. Kumanyika, S., \& Grier, S. (2006). Targeting interventions for ethnic minority and low-income populations. The Future of Children, 16(1), 187-207.

49. Duke, N. K. (2000). For the rich it's richer: Print experiences and environments offered to children in very low- and very highsocioeconomic status first-grade classrooms. American Educational Research Journal, 37(2), 441-478.

50. Newman, S., \& Celano, D. (2001). Access to print in low-income and middle-income communities. Reading Research Quarterly, 36(1), 8-26.

51. Currie, J. (2005). Health disparities and gaps in school readiness. The Future of Children, 15(1), 117-138.

52. Williams, D. R., \& Jackson, P. B. (2005). Social sources of racial disparities in health. Health Affairs (Millwood), 24(2), 325-334.

53. Flores, G., \& Tomany-Korman, S. C. (2008). Racial and ethnic disparities in medical and dental health, access to care, and use of services in US children. Pediatrics, 121(2), e286-e298.

54. Blendon, R. J., Buhr, T., Cassidy, E. F., Perez, D. J., Hunt, K. A., Fleischfresser, C., et al. (2007). Disparities in health: Perspectives of a multi-ethnic, multi-racial America. Health Affairs (Millwood), 26(5), 1437-1447.

55. American Academy of Pediatrics. (2006). Identifying infants and young children with developmental disorders in the medical home: An algorithm for developmental surveillance and screening. Pediatrics, 118(1), 405-420.

56. Sand, N., Silverstein, M., Glascoe, F. P., Gupta, V. B., Tonniges, T. P., \& O'Connor, K. G. (2005). Pediatricians' reported practices regarding developmental screening: Do guidelines work? Do they help? Pediatrics, 116(1), 174-179.

57. Regalado, M., \& Halfon, N. (2001). Primary care services promoting optimal child development from birth to age 3 years: Review of the literature. Archives of Pediatrics and Adolescent Medicine, 155(12), 1311-1322.

58. Zuckerman, B., Khandekar, A. (2010). Reach out and read: Evidence based approach to promoting early child development. Current Opinion in Pediatrics, doi: 10.1097/MOP.0b013 e32833a4673.

59. Theriot, J. A., Franco, S. M., Sisson, B. A., Metcalf, S. C., Kennedy, M. A., \& Bada, H. S. (2003). The impact of early literacy guidance on language skills of 3-year-olds. Clinical Pediatrics (Philadelphia), 42(2), 165-172.

60. American Academy of Pediatrics. (2005). Quality early education and child care from birth to kindergarten. Pediatrics, 115(1), 187-191.

61. DiGiuseppe, D. L., Aron, D. C., Ranbom, L., Harper, D. L., \& Rosenthal, G. E. (2002). Reliability of birth certificate data: A multi-hospital comparison to medical records information. Maternal and Child Health Journal, 6(3), 169-179. 